\title{
PLEASE REFERENCE:
}

Degen, M. \& Lewis, C. (2020) "The changing feel of place: the temporal modalities of atmospheres in Smithfield Market, London", Cultural Geographies, accepted.

The changing feel of place: the temporal modalities of atmospheres in Smithfield Market, London

\begin{abstract}
Within the context of recent debates around urban atmospheres, this paper examines the situatedness and partiality of urban experiences. Drawing on an ethnographic study of the Smithfield Market area, a neighbourhood undergoing a period of rapid urban regeneration as part of the 'Culture Mile' in the City of London, we explore how different individuals experience the changing feel of place. By focusing on the felt body, the paper analyses the ways in which individuals with different attachments to the neighbourhood respond to the impending urban change and draw on selective temporal modalities of atmospheres in order to make specific claims to place. In particular, we identify three temporal modalities of atmospheres: the selective feel of the past, the contentious present feel and the ambivalent future feel. The paper thus argues that studies of urban atmospheres need to pay more attention to the manifold bodily capacities, personal and social histories which mediate and position in diverse ways how places are experienced. More generally, the paper makes an intervention into debates on urban atmospheres by analysing empirically how the variable interactions between sensory and temporal qualities produce diverse atmospheric constellations for different individuals.
\end{abstract}

Keywords: atmospheres, temporality, urban regeneration, feel of place, senses, felt body, Smithfield Market, Culture Mile 


\section{INTRODUCTION}

In the summer of 2017, the Smithfield Market area was designated part of the 'Culture Mile', a partnership endorsed by the Corporation of London including the Barbican, the London Symphony Orchestra, the Guildhall School of Music and Drama and the Museum of London (www.culturemile.london). The aim of this cultural regeneration project is to link up 'organisations across the City and beyond to work together on an unprecedented scale to build a world leading learning destination.'1 As part of this new cultural area, the Museum of London is planning to relocate in 2023 to West Smithfield, which currently contains derelict Victorian buildings that adjoin Britain's longest running wholesale meat market. It is expected that the move will increase museum visitor numbers from 900000 a year, to over 2 million. $^{2}$ To improve access to the area and promote the area as a cultural destination where "creativity is fast becoming the most valuable currency"3, two new Crossrail Stations will open in Farringdon and Moorgate in 2019. How this physical transformation will affect the area's identity is uncertain, as one planner involved in the redevelopment explained: 'There are certain facts that say that certain things will change, but it's still very unknown how the feeling will change. The buildings will change because there's a museum coming. No one will ever really be able to predict its impact and there's a lot of uncertainties about what that future looks like for the area, in terms of feeling, social life and atmosphere.'

This paper interrogates this changing feel of place by drawing on empirical research developed in collaboration ${ }^{4}$ with the Museum of London in 2017. The study investigated the changing sensory identity of the Smithfield area from the past to the present, asking how it was perceived and how it might evolve as the Culture Mile develops. It is well established in social science literature that urban development processes transform more than the built environment and spatial configuration of neighbourhoods as they also dramatically redefine the somatic and temporal landscape of cities - in other words, how they are experienced by different individuals. ${ }^{5}$ Understanding the feel of place has been of enduring interest to human geographers. Phenomenological approaches such as those by Tuan ${ }^{6}$ or Relph ${ }^{7}$ analysed the interaction between experiences and the making of places. Tuan, in 
particular, argued that individuals transform 'abstract' spaces into places through routine, sensory, emotional and embodied engagements with their material surroundings over time which provide specific meanings and distinct place attachments to them.

A number of scholars have expanded such approaches, most significantly Doreen Massey's ${ }^{8}$ work on the interaction between space and time which informs our theoretical approach. More recent research in geography has developed understandings of changing everyday sensibilities of place by exploring what Thrift $^{9}$ called a 'geography of what happens', in order to draw "attention to the matterings, the complex emergent worlds, happening in everyday life". ${ }^{10}$ In this context atmosphere has developed as an umbrella term, which address the relational dynamics between bodies and the surrounding material environment ${ }^{11}$. Böhme famously states that atmospheres are produced "in the relationship between environmental qualities and human states". ${ }^{12}$ However, as Gandy points out, atmosphere remains a 'fuzzy' and ill-defined concept. ${ }^{13}$ And many critics, such as McCormack, emphasise the indeterminate character of atmospheres, arguing that they are "distributed yet palpable, a quality of environmental immersion that registers in and through sensing bodies whilst also remaining diffuse, in the air, ethereal". 14

This paper contributes to these debates by arguing that while we consider atmosphere a useful concept for describing the relational dynamics of people and their material environments, it needs to be conceptualised as plural, diverse and multiple. ${ }^{15}$ While we acknowledge that urban life is a constantly shifting, multifaceted experience, we argue that places undergoing intense urban change elicit a multiplicity of overlapping atmospheres which are experienced differently by the diverse users of the city depending on their attachment to the place. ${ }^{16}$ Bringing into dialogues Gandy's suggestion to explore atmospheres seldom discussed "temporal coordinates... and the varied social and historical contexts within which atmospheres are perceived and generated" 17 and Böhme's phenomenological inspired work that emphasizes the role of the sensing, felt body as atmospheres need to be "sensed to exist" ${ }^{18}$, we investigate how Smithfield's manifold atmospheres are underpinned by distinct temporal modalities. These are: a selective feel of the past, a contentious 
feel of the present, and a ambivalent feel of the future and show how they shape people's feelings of (dis-)attachment to place.

The first part of the paper introduces Smithfield, explaining how the area has a distinctive feel of place due to the history of the market and its unique topography. The second section argues that much research on atmospheres has neglected to pay sufficient attention to the temporal dynamics of urban atmospheres. With an emphasis on embodiment, we expand understandings of atmosphere by stressing their variability and situatedness, as well as highlighting their temporal nature. We then elaborate these points in the third section, by drawing on our empirical findings to illustrate how individuals, engaged in various practices, with different senses of place and attachments to Smithfield, draw on distinct temporal-sensory experiences to describe their particular feel of place.

\section{The case study: Smithfield Market}

Smithfield Market dominates a large area between Farringdon and Barbican underground stations in central London. Our analysis of the sensory atmospheres in and around the market building reveals that they are redolent of the areas varied history. Surrounding street layouts have remained unaltered since 1870 and follow mainly a medieval pattern. Compared to the four streets surrounding the market which are busy with London's restless traffic, a quieter, calmer atmosphere emanates from the surrounding narrow streets and passageways which are home to medieval buildings such as the $11^{\text {th }}$ century St Bartholomew the Great church. To the east, the Barbican housing estate which was built in the 1960s, boasts three brutalist concrete towers which dominate the sky line. To the West, a glittering façade of austere high glass buildings constructed in the 2000s. The views of cranes, noise of drilling and construction and wafts of dust drifting across the site signal the sites ongoing urban redevelopment.

As Britain's largest and longest running wholesale meat market Smithfield operates mainly at night-time from a grand Victorian building which expands over three blocks. As our ethnographic observations showed, in the daytime Smithfield Market lays dormant, a quiet background to the busy flows on office workers, students, tourists 
and hospital staff who walk through the steel iron avenue or around its imposing structure. The City of London has a daily inflow of 482.320 visitors during the week, but only houses 7500 residents $^{19}$. At night, as city and creative industry workers leave the many pubs and bars of the area, the market gradually awakens. From 10pm onwards enormous white lorries from across Europe arrive, jamming up the surrounding narrow streets. Around the market fervent activity begins, as rows of cow and pig carcasses are transported into the cool houses. Market workers in white gowns carry boxes of chicken carcasses and offal, and the first customers arrive as the market's doors open at 2am from $5^{\star}$ hotels and local restaurants.

Image $1 \& 2$ here

Our research explores the ways in which atmospheres at Smithfield Market were experienced differently in relation to individual's personal relationships, their social histories and sense of attachment to place ${ }^{20}$ For example, Damian, an engineer who had worked on the Crossrail development project since 2012, explained how the unique composition of historic buildings and the size of Smithfield's Victorian market made the site challenging for his work building the new trainline. However, simultaneously, he described how the area had 'grown' on him due to the sensory juxtapositions which shape its idiosyncratic character:

'It's just utterly bonkers having a meat market, something that size, just in the street. It blocks up the area and everything else. But people seem to just accept it. It's sort of a corner of London where people say: oh, it's the meat market! And there's people out in their best gear and going to Fabric night club, and the clubs and pubs and everything else around there, and they are walking over carcasses. It's just bizarre!'

Damian's remarks illustrate how his assessment of the market was informed by his relatively recent encounter with the area and current concerns as an engineer. Diana on the other hand, a historian and long-term resident, interpreted the feel of Smithfield from a different position alluding to what she perceived as the 'strong psychogeography' of the area: 
'The history is alive. Whether that's because of the buildings and the fact that there are a few cobbled streets, and there's no real sort of through traffic going backwards and forwards as there is elsewhere in the city. But it's a little bit, well ghostly isn't the right word. But you do get a sense of history here. More so than other bits of the City. But nevertheless, it's not a dead place. It's sort of special!'

Both research participants described Smithfield with a similar depth of affection. However, while they alluded to Smithfield's atmosphere they did so by emphasising different sensory-temporal dynamics which were mediated through their different connections to place. In order to explore these temporal dynamics further, our analysis examines how urban atmospheres are felt in a highly variable manner. At the same time, we suggest some shared or collective forms of experience, created a distinctive feel in Smithfield compared to other parts of the inner city. For example, many of our respondents agreed that the dense juxtaposition of history, new developments and urban change made Smithfield unique. However, as we argue in the next section, much of the literature on atmospheres has paid little attention to the ways in which individual's experiences of atmospheres differ and reasons for this.

\section{Atmospheres, temporality and the felt body}

Our starting point for conceptualising how atmospheres are reconfigured through particular bodies and distinct temporal framings is Massey's ${ }^{21}$ understanding of space as relational. Her work suggests that places always contain a plurality of spatial meanings and are always under construction. ${ }^{22}$ Massey explains that space is a fluctuating, constantly changing entity which is produced by a range of dynamic relationships between different times (past, present, future), and is created in relation to the heterogeneous practices and engagements of its users. She argues:

"Precisely because space [...] is a product of relations-between, relations which are necessarily embedded material practices which have to be carried out, it is always in the process of being made. It is never finished; never closed. Perhaps we could imagine space as a simultaneity of stories-so-far". ${ }^{23}$ 
There are two aspects of Massey's theorisation on space that are particularly relevant to our argument. First is Massey's focus on space as a process that is constantly under construction as it is performed through time and second, her emphasis on bringing time and space together to understand the making of places as lived configurations. Yet, as she points out this:

"does not mean that [time and space] are identical (for instance in some undifferentiated fourdimensionality), rather it means that the imagination of one will have repercussions (not always followed through) for the imagination of the other and that space and time are implicated in each other...and that it has reverberations for thinking about politics and the spatial". ${ }^{24}$

Here, Massey clearly states that our imaginations of places, whether in the past or future, influence our personal relationships to the current place we are situated in and which is evidenced in our fieldwork. ${ }^{25}$ Massey continues by arguing that rather than attempting to capture the passing moment, time, within a spatial order, we need to think of different ways to imagine, write and bring to the fore 'space-time':

"Space conquers time by being set up as the representation of history/life/the real world. On this reading space is an order imposed upon the inherent life of the real. (Spatial) order obliterates (temporal) dislocation. Spatial immobility quietens temporal becoming.[...]For in the very moment of its conquering triumph 'space' is reduced to stasis. The very life, and certainly the politics, are taken out of it". ${ }^{26}$

As Massey points out, the moment we try to capture space and represent it in a particular moment in time, through academic analysis, we reduce it to stasis. So, how are we to research, analyse and write about dynamic places which are constantly in flux? Massey suggests imagining 'the event of place', in other words approaching place as a 'temporary constellation'. ${ }^{27}$ Thus, as our research illustrates, space is made up of a series of material, social, political elements that momentarily coalesce in the particular experiences of place of individuals'. 
Massey's understanding of place as having 'processual feel' has been further developed by the concept of atmosphere ${ }^{28}$ which emphasizes the affective sensations of place that emanate from the interaction between the environment and a sentient body. Atmosphere extends Massey's temporary constellations of place, by drawing attention to different experiential intensities which fluctuate according to particular senses of temporality. ${ }^{29}$ McCormack argues that one of the conceptual problems with describing these experiential intensities as atmosphere is the conflation of its two meanings in understandings of places: a) the meteorological sense and $b$ ) the affective sense as "intensities of feeling". ${ }^{30}$ He suggests to distinguish between these intensities in terms of "affect, as a field of pre-personal intensity; feeling, as an intensity registered in sensing bodies; and emotion as the socio-cultural expression of that felt intensity". ${ }^{31}$ While there has been much written about affect and emotion, the sensory and embodied felt dimension of atmosphere has been generally taken granted rather than examined. ${ }^{32}$ Rose et al hence suggest paying more attention to subjective experiences of the built environment, through the concept of feeling to offer a "richer and more complex sense of the human entrainment in buildings". ${ }^{33}$ Feeling, Rose et al contend, "is a crucial component in the human experiencing of town centres" and has three components. ${ }^{34}$ Firstly, the feel of buildings as a "more or less intense field of assemblages"; secondly the feel in buildings which refers to the "things people feel in relation with both the building and their own memories" and thirdly the feelings about buildings "reflexive opinions that people hold of buildings". ${ }^{35}$

While these are helpful distinctions to analyse the subjectivity of experiences, and are certainly reflected in the responses of our research participants, the temporal relations that underpin these feelings are implied rather than elaborated upon. An exception is Buser's ${ }^{36}$ work which provides a discussion of the benefits of paying attention to the temporal characteristics of atmospheres in processes of urban change. His study shows the changing atmospheres in a Bristol roundabout which transforms from a derelict and desolate place by the 1990s, associated with antisocial behaviour, to a vibrant a convivial space through the work of local community groups. Buser concludes that "atmosphere is the state of affairs of actualisation of a particular spatial-temporal condition, be it lively, dangerous, peaceful and so on"37, 
showing that atmospheres are never uniform or fixed, but are always circumstantial, underpinned by temporal dynamics, and as we argue are constituted through felt bodies "living through things". We expand these approaches by arguing that atmospheres are produced and felt through the entanglements between distinct sentient bodies in space-time.

Focusing on temporal-sensory experiences as feelings allows us to move away from the notion of atmosphere as a general concept and to focus on how atmospheres can be conceptualised as individually felt and also as context specific. ${ }^{38}$ The work of the German philosopher Böhme's is particularly relevant here as he conceptualises atmosphere as emerging precisely through the co-presence of subject(s) and object(s). ${ }^{39}$ Hence atmospheres are not free-floating but always something that "proceeds from and is created by things, persons and their constellations". 40 Indeed, atmospheres "without the sentient subject...are nothing". ${ }^{41}$ It is important to dwell for a moment on Böhme's notion of the sentient subject. He distinguishes between the German concept Leib, meaning corporeality, to explain how atmospheres are not felt by a universal body but are felt through a Körper, which refers to an individual body. He specifies that atmospheres are felt and lived through particular, sentient bodies which are geographically, temporally and culturally situated and therefore filter individual experiences of place. Sensory dimensions make up what we experience as the atmosphere of place which is entwined with personal moods or prior experience as we interact as embodied beings with our environment. ${ }^{42}$ Böhme concludes that atmospheres are hence "felt presences...in space" which "shape experiences and affective and emotional connections or engagements to particular places". ${ }^{43}$ We explore through our empirical research how atmospheres are felt experiences and contingent upon different personal and social circumstances and relations to place that are framed through particular temporal modalities. But first, we provide a description of our methodological approach.

\section{Methods}

We devised a multi-methods approach to capture the changing and multiple sensory and temporal engagements that emanated from different user groups in the site. We used a combination of ethnographic observations over a six-month period, walkalong interviews with 21 key stakeholders, vox-pop surveys with 110 individuals using the area, streetscape photography, contemporary sound recordings and 
textual and historical data analysis. This mixed methods approach produced sensory rich and temporally layered types of data, which was necessary as the sensory is often defined as 'seen but unnoticed' and difficult to verbalise. ${ }^{44}$

Over time we developed a detailed ethnography where we spent extended periods of time around Smithfield market in order to 'appreciate the meaningfulness of our sensory experience of the world, and the importance of the skilled practices through which we make sense of the lifeworld through our senses'. ${ }^{45}$ In order to become attuned to the sensory and temporal character of the area we carried out walk-along interviews led by our participants. ${ }^{46}$ Sharing a walk with someone involves a temporal and spatial co-presence in the world, where the otherwise unique, mysterious, body falls into a rhythm with another and creates a common form that becomes familiar to both. ${ }^{47}$ As Thibaud has argued walking is the best and most widely documented way of exploring practices and daily activities - in other words, atmospheres can be studied when focusing on the related sensory phenomena in accordance with the specific places or practical activities that they affect. The multisensory nature of emplaced memory implicates smell and taste in establishing connections among the past, present, far and near ${ }^{48}$. Therefore, the effect of being in place is heightened by walking through routes that are coloured with meaning and accrued from the past.

The data was examined through a cross-sectional analysis, with particular attention on how different experiences where accounted for verbally, visually and through other sensory experiences. This approach followed an 'investigative epistemology,' remaining open to the themes arising, rather than ruling out any data source in an a priori way. ${ }^{49}$ Instead of integrating parts of an empirical study in a formulaic and predesigned kind of way, this involves thinking, imagining and writing across and through different themes of the research. ${ }^{50}$ In this paper, we draw primarily on our walk-along interviews, vox-pox surveys and ethnographic observations. The next section explores how feelings of place are underpinned by particular temporal modalities. 


\section{Constructing the Feel of Place}

From interviews with users and our observations it was clear that a variety of distinct atmospheres emerged over the daily and weekly cycle of the Smithfield area and also due to the ways different individuals and groups engaged with the neighbourhood. Hence, as much as atmospheres are 'palpable, shared and seemingly durable affective sensations, they are always open to transformation'. ${ }^{51}$ Our analysis indeed reveals that the feel of place is continually changing and fluctuating for individuals as atmospheres are made sense of in relation to particular subjective understandings of time in place. This illustrates Massey's argument of how individuals' sense of place develops through the dynamic relationship between different times and their practices and emotional links to places. ${ }^{52}$ We identify three temporal modalities: a selective feel of past, a contentious feel of present and the ambivalent feel of the future, each of which emerged as themes in our research. While we separate them here for the purpose of our analysis, these temporal modalities overlapped in our findings.

\section{a. The Selective Feel of the Past}

The identification of a 'historic atmosphere' played a big part in the majority of our research participant's sense of attachment to Smithfield. As Buser ${ }^{53}$ states, atmospheres can be expressions of shared or collective forms of being and moving through the world. For example, a town-planner working on the area argued:

'I think the market is the soul of the area and always has been....In terms of London as a whole, there's nowhere else like this. It's the most incredible place of medieval buildings and sort of activities here that go way, way back. It's extraordinary. So, this is a very, very special place.'

Similarly, across the range of our interviewees, the area was experienced very much through its historic architecture, as illustrated through these place descriptions: '1000 year churches nestled up to Victorian markets', 'little cobbled medieval streets' or 'historical, character buildings'. Yet, at the same time, research participants discussed atmospheres from an individual and situated perspective, by drawing on distinctive sensory experiences and temporalities, supporting Buser's argument that 
individuals arrive at research sites with diverse personal and social experiences that "stimulate divergent affective and emotional responses" 54.

For example, Adam a creative worker who worked in Smithfield for 5 years and now works in Amsterdam described Smithfield nostalgically as 'the forgotten edge of the City'. He defined its feel affectionately as a 'grimy back lands vibe'. While he accepted that in the future, the area would be better connected and more accessible he was also concerned how the area was already changing:

'When I was there five years ago it felt it was yours - you thought it was your kind of London - you were proud of how grotty it was. My fondest memories are that I felt that I had some sense of ownership as a worker and how the area is full of secrets.'

We can identify here a particularly nostalgic construction of Smithfield's past that links the lack of access, abandonment and dereliction of the place with a strong sense of belonging. This nostalgic sense of the past was also evident in many of our vox pop interviews. About $70 \%$ of respondents used adjectives such as 'historical', 'authentic', 'traditional', 'local' to describe the most salient features of the Smithfield area illustrating, similar to the quote above, the perception of a distinctive identity of Smithfield which needed protecting. This sense of history was understood in relation to an atmosphere which was perceived by the 'untouched' physical environment. Interviewees did not discuss the fundamental changes which have taken place in Smithfield's history as much, such as the repeat attempts of urban sanitation over the centuries or changes to the social fabric of the area. Instead, they were keen to stress the sensory continuities between past and present and emphasize the uniqueness of Smithfield compared to the rapidly changing city.

The sense of historical continuity was evident in Margaret's narrative, a long-term resident in her fifties. She drew on the visceral qualities of the existing environment and an imagined past when describing the Smithfield Market area:

'I like the human scale of it, the historic buildings, the churches. One used to be able to wander freely in the square in the hospital, so you're in an 18th 
century environment, and you can just see Hogarth's staircase poking through the window. I like that, the history and the scale of it.'

This example reveals how it is the interaction between felt bodies and buildings that shape a strong sense of embodied historical feel in the present. As Margaret further elaborated, this historic sensory feel served as a contrast to contemporary life: 'I like the fact that the meat market has been so solidly meat market, that they so clearly do what they do and they sit about in the cafes and I like that resilience to modern life. They seem to inspire a particular sense of character.' Sandra, who worked at the market, emphasized that the atmosphere of the market was a 'relic' from a former time that has disappeared in many areas of the city:

'It was very much a part of everyday London life 'cos people used it. I don't think they do quite so much, but it's in many ways, a bit of a hangover from London's past... You feel like this is the last sort of bastion of gritty London.'

Similarly, many of our other participants commented fondly on the sensory characteristics of the area elicited by the market, including the smells of 'meat fat it's a very cold smell', noises 'you can hear Cockney and all kind of languages' and appearance 'the blood spluttered gowns of market workers'. We were told that these sensory markers were an important reminder of working-class traditions in the City of London which were perceived as fast disappearing.

Image 3: A juxtaposition of architectural styles

Other respondents, such as Diana, a resident who had worked in the area since the 1990s, drew on personal memories to discuss her sense of attachment to Smithfield. Her experience of space was shaped through personal associations and narratives. Sensory perceptions were drawn upon to link the present sentient body with that of past experiences as this quote illustrates:

'I know that [there is] a different mood at night time. When I was younger and used to be here, it gets a bit more sort of hedonistic. Obviously, it was all Fabric (the nightclub) and the sense of the meat market being a 24 hour 
market. So, it's probably true more so than in a lot of other areas that here the night time mood is a little bit different to the day time one.'

We can see in all these accounts how urban change and individuals' experiences of the area's transformation intertwine with memories of the past ${ }^{55}$ and individuals' feelings in, of and about the area which weave through the understandings and evocations of present sensory experiences showing how "the human ... is performed with buildings". ${ }^{56}$ Yet, Smithfield's unique historic atmosphere was discussed across our interviewees, the precise features of this imagined past were referred to in a vague way and instead a selective feel of the past emerges. Different individuals put varying emphasis on the importance of architectural features, social relations, sensory experiences, and personal memories. We found that professionals such as planners, artists, architects and conservationists focused strongly on the preservation and reuse of the existing architectural fabric. Whereas traders, businesses, visitors and residents emphasize the importance of preserving and experiencing the area's social history, everyday practices, traditions and rituals. These findings illustrate how diverse user groups with different links to Smithfield draw on specific features of history to characterise their personal feel of place. Individuals construct particular and partial readings of atmospheres which are mediated through their embodied feelings and social histories and in order to make particular claims to place.

\section{b. The Contentious Present Day Feel}

For other participants, the historical significance of the area was more contentious. In particular, some participants argued that the market was 'out-of-place' in the contemporary city. The dilapidated parts of the building, where the Museum of London will move into, were regarded as unattractive and redundant. For some of our interviewees, the atmosphere in the derelict, run down areas of the market was a source of anxiety. For example, Diana commented on how she liked the historical features of the area, but was concerned about the buildings falling into further state of disrepair:

'Once an area sort of tips over into whole dereliction, then it's a problem. Then you really do need either major money to do it up and then, you are in danger 
of the thing getting corporatized or knocking down old buildings. So, a little bit of dereliction, yes. Well, it's almost like you don't want too much sort of corporate rebuilding 'cos otherwise, you destroy the soul of the place.'

For Diana, the feel of place was directly related to a changing physical environment. She felt that there was a delicate balance between maintaining the old, historical buildings and allowing the inevitable redevelopment without ruining the 'soul' of the area. Similarly, when asked to describe the character of the area most of our interviewees and vox pox respondents argued that Smithfield was defined by a juxtaposition of sensory experiences such as 'dirty but also busy and interesting', 'inviting smells that come out of the cafes, that's quite nice', 'warm beer coming out of a pub', 'smell of old buildings coming out of the churches' to mention a few.

Image 4: Smithfield's streetscape

Graham, a local conservationist argued that there were lots of practical problems with having an Victorian wholesale market operating in contemporary London. These included, heavy traffic and environmental pollution in relation to the noises and smells from the market trading. He felt that although the market had been an important institution in the past, it was no longer viable:

'But then, the Museum of London came into the equation. So, it began to make sense to use it in a cultural way. We'd always had lots of schemes for how think about the future of the market because it's not going to succeed as a 'dead meat market' in the long term. It's wrong, especially because of the traffic it generates. These big heavy trucks coming in down what are now residential streets in the middle of the night. It's just wrong. The city has changed.'

We can see here how Graham contrasts sensory - spatial considerations with temporal dynamics: a 'dead meat market' - a city that has changed, to argue why a cultural regeneration makes sense. However, the majority of our participants liked the area precisely because of the juxtaposition of atmospheres which characterised the area with a 'vibrant', 'alive', 'special', 'eclectic', 'unique' character. When our respondents were asked to discuss the atmosphere in more detail they tended to 
describe one key feature, namely the various, and often parallel, activities taking place in the area where no group dominates the uses of publics place. In particular, they described how over the 24 hour cycle of a day - very different atmospheres emerge and disappear:

'one minute, it can be deathly silent and there's nobody about. And then, you sort of step out and there's meat traders and the place is just utter chaos. Absolute chaos. There are wagons, there's people and everything' (manager at Crossrail site).

These overlapping, shifting atmospheres were generated by the diverse social groups and their uses of the space. Most interviewees remarked on observing the practices of a working meat market. This included, seeing trucks delivering carcasses, butchers dressed in white uniforms carrying meat and cleaners in navy blue outfits hosing down the concrete paving surrounding the market. Such observations stood in sharp contrast to the site of suited city workers walking to work or socialising outside the pubs, creating a distinctive feel of place made up of contrasting sensory experiences. While many visitors and creative workers described the area as vibrant, most workers we interviewed in local businesses surrounding Smithfield market such as shops, restaurants, cafes, barbers of hairdressers had a very different experience. They thought that the area was boring and dull rather than edgy and exciting.

Image 5: The view from a restaurant looking out

One young hairdresser, who was working in a local business described the view from the window of the area surrounding the market as grey, unchanging and monotonous. She explained how she enjoyed seeing some greenery outside the window from plants on the roadside but would have liked a more varied view. The small shop was lined with mirrors, so even when she was cutting someone's hair the street view was dominant. She described how most the bars in the area felt 'boring and full of suits' - indicating clear feelings of non-belonging. Asked whether she could recommend any cafes locally, she told us that her boss had ordered her not to leave the shop, so she was stuck inside. This interview highlighted a strong feel of 
boredom and frustration by some workers and how atmospheres are always shaped by individual contexts and influenced by class positions and social histories.

\section{c. The Ambivalent Future Feel}

In areas of urban development discussions about the present space, are shaped by different imaginations and aspirations about the future ${ }^{57}$. In this section, we focus on two opposing feelings that were held in tension with each other. When participants were asked how the regeneration would transform the area most expressed simultaneously a feeling of loss and expectation. Respondents drew on a range of atmospheric qualities to make sense of this ambivalence. This was particularly clear when we asked them to reflect on how they would describe Smithfield market as an object. They mostly answered figuratively with descriptions that highlight the sensory and social heterogeneity of the area such as 'a melting pot of experiences', 'a puzzle' or a 'a hearty fish pie'. An architect mused: 'a tree in mid-winter, the leaves aren't there, but it is about to renew - and come into spring'. This response reflects the sites current conflicting identities as a place in transition as well his own judgment that the area needs to change to develop.

Part of the aim to relocate the Museum of London to the new site in West Smithfield is to increase the museum's visibility and visitor numbers. While it is acknowledged that the relocation is part of the broader rebranding of the area as the new 'Culture Mile' and involves an extensive physical and social makeover, our interviews with museum staff, local authorities and architects revealed that this is underpinned by an attempt 'to hold onto the character of the area' (architect). Sensory experiences were key to this. As one of the architects appointed to develop the new museum site explained, he hoped to draw on sensory perceptions to connect the past to the present in the renovation of the building: 'At the bottom level of West Smithfield are still signs of the Romans. To think about the Romans gives us a very sensory engagement with the city. I have always argued that once you engage with the senses, the imagination is triggered.' The challenge for those involved in the redevelopment is to retain the 'unique feel of place' while simultaneously culturally rebranding the area ${ }^{58}$ into what has been described by planners as an 'upmarket destination' for the museum. 
Diana, the local resident and historian discussed earlier, drew on a range of sensory descriptions to express her concerns about the potential loss of atmospheres through the regeneration:

'One likes a little bit of dereliction because you don't want everything shiny and modern. It is pretty atmospheric in a very sort of ghostly, gothic way. And, it's rather wonderful. And half of me sometimes thinks: oh, it's a shame we have to sort of tidy it all up and make it all clean and shiny.'

Diana felt a sense of emotional attachment to the historic atmosphere of Smithfield but was also concerned that 'too much dereliction is not good for an area.' Similarly, Nicola, another long-term resident was worried that the area may turn into 'an elite space, over managed. Museums can be over managed and I hope that doesn't happen. I just want this kind of muddle to go on'. Yet, within the same interview Nicola also conceded that as a material, felt presence: 'the market is a bit of a barrier to cross the neighbourhood.'

While there is a clear sense of expectation about how the re-branding of the area will affect local businesses, there were also a lot of pragmatic concerns about how the market could coexist alongside the new cultural facilities. When asked how the regeneration of the area will affect the market Tina, a market worker reflected:

'The Planning department from the Corporation of London like the idea of the meat market. But when you start to say to them, "Hang on a minute. How is the improvement of the area gonna impact our forklift trucks?" or this, that and the other, then they are not really sure. Or they don't like ... those sorts of compromises.'

Despite meat trading activities declining over the last 30 years ${ }^{59}$, the market still played an important role in the surrounding local economy. For example, there were a number of 24 hour cafes catering for market workers and customers, as well as gourmet restaurants which use branding, such as butcher themed decorations, to make a link to Smithfield's. Many of our vox-pox respondents also expressed 
concerns that the regeneration might erase the unique feel of place. While only a few respondents had seen animal blood on the streets, the smell of raw meat and sight of carcasses were described as 'part and parcel' of the area and provided 'a bit grit, a bit of edge'. These sensory experiences were an integral element of Smithfield's distinctive landscape which contrasted starkly to the atmosphere of 'corporate inner city: 'It's got a bit of bite to it... This place is alive at 3am in the morning and everyone is saying 'fuck off' everywhere. You've got weird little cocktail bars around the corner underground. There's the market just around the corner. It's all this mash of...it just feels it's got that little edge to it, which is interesting' (vox pox 16/6/2017).

The public inquiries in 2005 and 2014 to stop attempts to demolish West Smithfield highlighted in particular the value of the sensory landscape. The inquiries were organised by local heritage campaigners who argued that the market buildings made 'a significant contribution' to the character and appearance of the area ${ }^{60}$. As a study commissioned by English Heritage ${ }^{61}$ stated: "Our main purpose is to ensure that its fragile identity - defined by its architectural character, streets, places and activity patterns - is respected and reinforced rather than ignored." However, ongoing changes to the area are noticeable, through the new residential developments being built, as well as new hotels, offices as well as the upgrading of Farringdon station. While at the time of our research a local planner explained that complex negotiations were taking place to make it possible to make the working market stay as 'there is still a feeling that they belong to the area', it was announced in 2019 that the market will relocate to Barking. ${ }^{62}$ When the new transport interchange between Crossrail, the London Underground and Thameslink opens it is estimated that 140 trains per hour will pass through with up to 27 million passengers expected to move through Farringdon Station every year. ${ }^{63}$ The impact that new visitors and residents might have on the feel of the area is uncertain: 'In 2 years' time, we will be in a different world. It's very hard to predict what will happen.' (Graham, local campaigner). As one local authority planner explained, the cultural regeneration will lead to more exposure and more people visiting the area:

'This will definitely change the feeling of it being a very quiet, kind of secret place. It will become a lot more exposed...it's inevitable. So, I think that when the museum finally moves here... this area will lose that kind of secret, hidden feeling. It will just 
become another kind of cultural destination, which is a shame, but it's part of the transition of how the landscapes have to evolve to keep on kind of existing.'

Implicit in this planner's concerns were ambivalent feelings about the forthcoming regeneration. The planner's conflation of changes to the built environment, working practices and overall feel of the place illustrates why the concept of atmosphere is useful to make sense of how places unfold. The concept of atmosphere helps to amalgamate the material, social and emotional understandings of the city as a common disposition, yet underpinned by multiple temporal dynamics within individuals' experiences of place. By emphasizing the felt body in our analysis, we have shown that atmospheres are both shared and subjective experiences: "The atmosphere of a city is the subjective experience of an urban reality that people in a city share. They experience this as something objective, as a quality of the city". ${ }^{64}$

\section{Conclusion}

Focusing on an area undergoing intense urban redevelopment, Smithfield Market, this paper has added to current debates of urban atmospheres by arguing for the partiality and situatedness of urban experiencing. Urban atmospheres are experienced diversely as they perform different social functions. Research on atmospheres commonly draws on non-representational theory, yet, as Gandy argues, this approach is limited because the sentient body evoked in such accounts tends to be devoid of gender, class, race or any other kind of social difference. ${ }^{65} \mathrm{We}$ agree with these reservations. By situating the felt body, as conceptualised by Böhme, at the foreground of our research, we have highlighted that while individuals use and occupy the same space, their bodily capacities, personal attachments and social histories mediate and position, in diverse and manifold ways, how they experience particular atmospheres of place. Indeed, our research has shown that individuals respond to the impending urban change by drawing on selective temporal modalities of atmospheres to make specific claims to space.

Using a temporal framework to analyse how atmospheres are felt has allowed us to identify three (inter-related) temporal modalities. Firstly, the selective feel of the past illustrated how individuals focused on different sensory markers of history to evoke distinct atmospheres. They weaved them together with personal memories to 
support their (dis)attachments to place. Secondly, the contentious feel of present highlights how the experience of atmospheres differed across user groups and across locations in Smithfield Market. We found that atmospheres mutated and blended over the 24 hour cycle of the day ranging from vibrancy to boredom depending on individual's relationship to and practices in Smithfield. Thirdly, we examined the ambivalent future feel which illustrated oscillating feelings between loss and expectation about the forthcoming redevelopment. All three temporal modalities were constituted simultaneously through past, present and future imagined features that shaped the sensual engagement with places illustrating how space is a 'simultaneity of stories-so-far'. ${ }^{66}$

Our findings have pointed to the multiplicity of multi-sensory experiences in the city and support Amin and Thrift's argument that "there is no one account of a single urban thing but rather a generative multiplicity of divergent and discontinuous lines of flights with their own spaces and times" 67 . Smithfield evoked strong feelings of attachment precisely because of the multiple uses of its public spaces and the 'juxtaposition' of sensory experiences such as old and new, clean and dirty, 'city' and working class to mention a few which means that not one sensescape dominates. This was regarded as possible because the area had not yet become overly sanitised, a feature which distinguished it from other places in central London. As Buser argues, multiplicity defines public space and that "to understand the political stakes of transformations in and around public space one must take account of how these atmospheres both emerge from and contribute to everyday experience". ${ }^{68}$ Thus, individuals' felt that they could be part of Smithfield's identity and feel part of a historical continuum. Indeed, our participants were concerned about the area's future redevelopment, pointing out that many other regenerated places in London had lost their identity as they were 'filled with the same shops and restaurant chains' resulting in 'artificial atmospheres' (vox pox 33).

Furthermore, by extending Massey's argument about conceptualising places as temporary constellations ${ }^{69}$ we have explored the micro-politics of space-time, the subtle claims to space and attachments that people develop in Smithfield which are imbricated in time. We suggest that exploring atmospheres' temporal dynamics reveals how place experiences and histories are not perceived as a smooth temporal 
progression in which one state is replaced by another or where one uniform atmosphere is experienced. Instead, our research shows how urban atmospheres are felt at an embodied, sentient level - framed by individuals' particular social histories and relationship to place, thus unfolding differently for each individual, and therefore need to be researched as plural, diverse and multiple embodied experiences.

\footnotetext{
${ }^{1}$ www.culturemile.london, accessed 14/1/2018.

2 Museum of London Strategic Plan 2018-2023, p.13.

${ }^{3}$ www.barbican.org.uk, accessed 3/2/2019.
}

4 The research presented in this paper resulted from an earlier research collaboration between the authors and curators from the Museum of London which brought together academics, urban professionals and city museum curators to understand the role of sensory research, see www.sensorycities.com.

${ }^{5}$ See: L. Law, 'Home cooking: Filipino women and the geographies on the senses in Hong Kong'. Ecumene, 8, 2001, pp. 264-83; M. Degen, Sensing Cities: regenerating public life in Barcelona and Manchester. (London: Routledge 2008); M. Degen \& G. Rose, 'The Sensory Experiencing of Urban Design: The Role of Walking and Perceptual Memory', Urban Studies 49.15, 2012, pp. 3271-3287; J.P. Thibaud, 'The backstage of urban ambiances: when atmospheres pervade everyday experience'. Emotion, Space and Society 15 (2015), pp3946.

${ }^{6}$ Y.F. Tuan, Space and place: the perspective of experience. (Minneapolis: Minnesota Press, 1977)

${ }^{7}$ E. Relph, Place and placelessness. (London: Pion, 1976)

8 D. Massey, For Space (London: Sage 2005)

${ }^{9}$ N. Thrift, Nonrepresentational Theory: Space, Politics, Affect. (Routledge, New York 2007).

${ }^{10} \mathrm{~K}$. Stewart, 'Atmospheric attunements'. Environment and Planning D: Society and Space, 29.3 (2011), pp.445.

${ }^{11}$ For an overview see: Edensor, T., \& Sumartojo, S., 'Designing Atmospheres: introduction to Special Issue'. Visual Communication, 14(3), 2015, 251-265; D. Trigg, 'Atmospheres, inside and out'. Environment and Planning D: Society and Space, 34(4), 2016, pp 763-773; A. Stephen, 'The affective atmospheres of nationalism'. Cultural Geographies, 23(2), 2016, pp181-198.

${ }^{12} \mathrm{G}$. Böhme, 'Atmosphere is the fundamental concept of a new aesthetic', Thesis Eleven, 36.1.,1993, p.114.

${ }^{13}$ M. Gandy, 'Urban Atmospheres'. Cultural Geography, 24.3, 2017, pp. 353-374.

${ }^{14} \mathrm{D}$. McCormack, 'Engineering affective atmospheres on the moving geographies of the 1897 Andree Exhibition'. Cultural Geographies 15.4. (2008): p. 415.

${ }^{15} \mathrm{M}$. Buser, 'The time is out of joint: Atmosphere and hauntology and Bodlam Castle'. Emotion, Space and Society 25, 2017a, pp. 5-13.

${ }^{16}$ See also M. Degen 2008. We deliberately use the term user following Lefebvre's (1991) critique of labelling those using and experiencing the city as inhabitants, tourists, and so on and thereby labelling or marginalising different forms of attachment to place, see also Bohme 2013.

${ }^{17}$ M. Gandy, 'Urban Atmospheres'. Cultural Geography, 24.3, 2017, pp. 353-374.

18 G. Böhme, Architektur und Atmosphäre, (Munich: Wilhelm Fink Verlag 2003).

${ }^{19}$ City of London Resident Estimates and Projections, Departments of the Built Environment, Corporation of London, 2018. 
${ }^{20}$ See also P. Simpson , 'A sense of the cycling environment: felt experiences of infrastructure and atmospheres', Environment and Planning A, 49.2, 2017, pp 426-447; M. Buser, $2017 a$ in relation to the variability of individuals' experiences.

${ }^{21}$ D. Massey, For Space.

22 D. Massey, For Space, p.9.

23 D. Massey, For Space, p.9.

24 D. Massey, For Space, p.18.

25 See also M. Degen \& G. Rose, 'The Sensory Experiencing of Urban Design: The Role of Walking and Perceptual Memory'.

${ }^{26}$ D. Massey, For Space, p. 30

27 D. Massey, For Space, 141.

${ }^{28}$ See also the related concept of ambiance, in J.P. Thibaud, 'The backstage of urban ambiances: when atmospheres pervade everyday experience'.

${ }^{29}$ Thrift 2004 in Koch and Latham 2012:522, see also K. Stewart, 'Atmospheric attunements'.

${ }^{30} \mathrm{D}$. McCormack, 'Engineering affective atmospheres on the moving geographies of the 1897 Andree Exhibition' Cultural Geographies, 15, 2008, p. 414.

${ }^{31}$ McCormack, ibid. p. 414.

${ }^{32}$ G. Rose, M. Degen \& B. Basdas, 'More on 'big things': building events and feelings', Transactions of the Institute of British Geographers, 35, 2010, pp. 334-349.

${ }^{33}$ Rose et all ibid, p.346.

${ }^{34}$ Rose et all ibid, p.346.

${ }^{35}$ Rose et all ibid, p.346.

${ }^{36} \mathrm{M}$. Buser, 'Atmospheres of stillness in Bristol's Bearpit', Environment and Planning D,

35.1, 2017b, p. 128.

${ }^{37}$ M. Buser, ibid, p. 128.

${ }^{38}$ But see: A. Stephen, 'The affective atmospheres of nationalism'.

${ }^{39}$ M. Bille \& K. Simonsen, Space and Culture, published online, 2019.

${ }^{40}$ Bohme 1993:122.

${ }^{41} \mathrm{G}$. Böhme 'The art of a stage set as a paradigm for the aesthetics of atmospheres' Ambiances' (2008) p.2, quoted in T. Edensor 'Designing Atmospheres'.

42 T. Edensor, 'Light design and atmosphere', Visual Communication, 14.3. (2015), p. 333.

43 Buser 2017, p.8.

44 Pink 2009; Degen \& Rose 2012.

${ }^{45}$ P. Vannini, Non-Representational Methodologies, (London: Routledge 2015) p. 321.

${ }^{46} \mathrm{M}$. Kusenbach, 'Street Phenomenology: The Go-Along as Ethnographic Research Tool', Ethnography, 4(3), 2003, pp. 455-485.

47 J. Vergunst, J., 'Rhythms of walking: History and presence in a city street'. Space and Culture, 13(4), 2010, pp. 376-388.

${ }^{48}$ A. Stevenson, A. 'We came here to remember: Using participatory sensory ethnography to explore memory as emplaced, embodied practice'. Qualitative Research in

Psychology, 11(4), 2014, pp. 335-349.

$49 \mathrm{~J}$. Mason, 'Re-using'qualitative data: on the merits of an investigative

epistemology. Sociological Research Online,12(3), 2007, pp. 1-4.

$50 \mathrm{~J}$. Mason, ibid.

${ }^{51}$ M. Buser, 'Atmospheres of stillness in Bristol's Bearpit', p. 128.

52 D. Massey, For Space.

${ }^{53} \mathrm{M}$. Buser, M. 'The time is out of joint: Atmosphere and hauntology and Bodlam Castle'.

${ }^{54} \mathrm{M}$. Buser, M. 'The time is out of joint: Atmosphere and hauntology and Bodlam Castle', p.6.

${ }^{55}$ M. Degen \& G. Rose, 'The Sensory Experiencing of Urban Design: The Role of Walking and Perceptual Memory'. 
${ }^{56}$ G. Rose, M. Degen \& B. Basdas, 'More on 'big things': building events and feelings', p. 339.

57 M. Degen, Sensing Cities.

58 M. Miles \& M. Miles, Consuming Cities (London:Palgrave 2004).

${ }^{59}$ C. Saphir, Review of London's Wholesale Markets, (DEFRA 2002).

${ }^{60}$ M. Herrera, Smithfield Market: Future, Potentials and Possibilities, Unpublished MSc City Design \& Social Sciences dissertation, (LSE 2011).

${ }^{61}$ Terry Farrell Architects, Smithfield-Farringdon; Reinforcing Urban Identity \& Character, (English Heritage 2007).

62 https://www.standard.co.uk/news/london/historic-smithfield-market-to-move-after-800years-in-central-london-a4126721.html, accessed 29/4/2019

${ }^{63}$ Rogers, A. (2018) Helical has won a $£ 120 m$ contract to develop space above Farringdon station ahead of the launch of the Elizabeth Line in December. City AM 26/3/2018.

${ }^{64}$ Bohme 2013:139.

65 M. Gandy, 'Urban Atmospheres'.

${ }^{66}$ D.Massey, For Space, p.9.

${ }^{67}$ A. Amin \& N. Thrift, Cities; Reimagining the urban, (Polity: Cambridge 2002), p. 28.

${ }^{68}$ M. Buser, 'Atmospheres of stillness in Bristol's Bearpit', p. 141.

${ }^{69}$ D. Massey, For Space, p.141. 